7

8

9

10

\title{
Optimization analysis of active solar still using design of experiment method
}

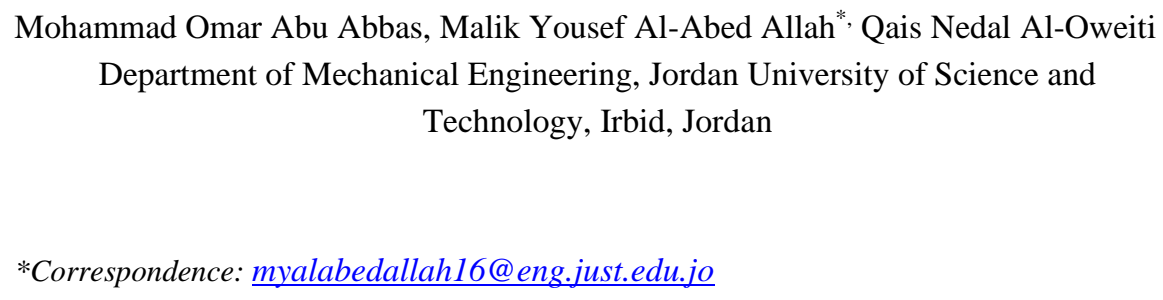

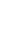
Mohammad Omar Abu Abbas, Department of Mechanical Engineering, Jordan University of Science and Technology, 22110, Irbid, Jordan, moabuabbas16@eng.just.edu.jo
Malik Yousef Al-Abed Allah, Department of Mechanical Engineering, Jordan University of Science and Technology, 22110, Irbid, Jordan, myalabedallah16@eng.just.edu.jo

Qias Nedal Al-Oweiti, Department of Mechanical Engineering, Jordan University of Science and Technology, 22110, Irbid, Jordan, qnaloweiti16@eng.just.edu.jo 
19 Key words: solar still, DOE, factorial design, thickness, productivity,

\begin{abstract}
:
Mathematical model for different configurations of active solar still has been analyzed. Theoretical analysis of energy balance for the active solar still components has been developed. A statistical manner for examination, evaluation, and optimizing the performance of the active solar distillation system with known input factors has been performed using the Design of Experiments (DOE) method. Some processes with input variables (factors) and predicted output variables (responses) have been evaluated. Input factors influencing the responses have been identified. The impact of each variable (factor) and integration of two factors at the same time (called interactions) have been estimated. Influences of various factors on a particular study at a time rather than performing different separated studies have been investigated. 11 variables (basin area, depth of saline water, external power, air blowing system, condenser material, condenser thickness, condenser area, insulation thickness, insulation material, ambient air temperature, and make-up water system ) have been studied to show their effects on three responses (mass output, saline water temperature and condenser cover temperature). The statistical results showed that the most significant factors affected on mass output (distilled water), respectively, were the external power, the depth of the saline water and the basin area of the active still. While the most influence factors affecting the saline water temperature and the condenser cover temperature were the depth of saline water, external power and air blowing system respectively.
\end{abstract}


https://doi.org/10.5194/dwes-2020-22

Preprint. Discussion started: 27 July 2020

(c) Author(s) 2020. CC BY 4.0 License.

\section{Nomenclatures:}

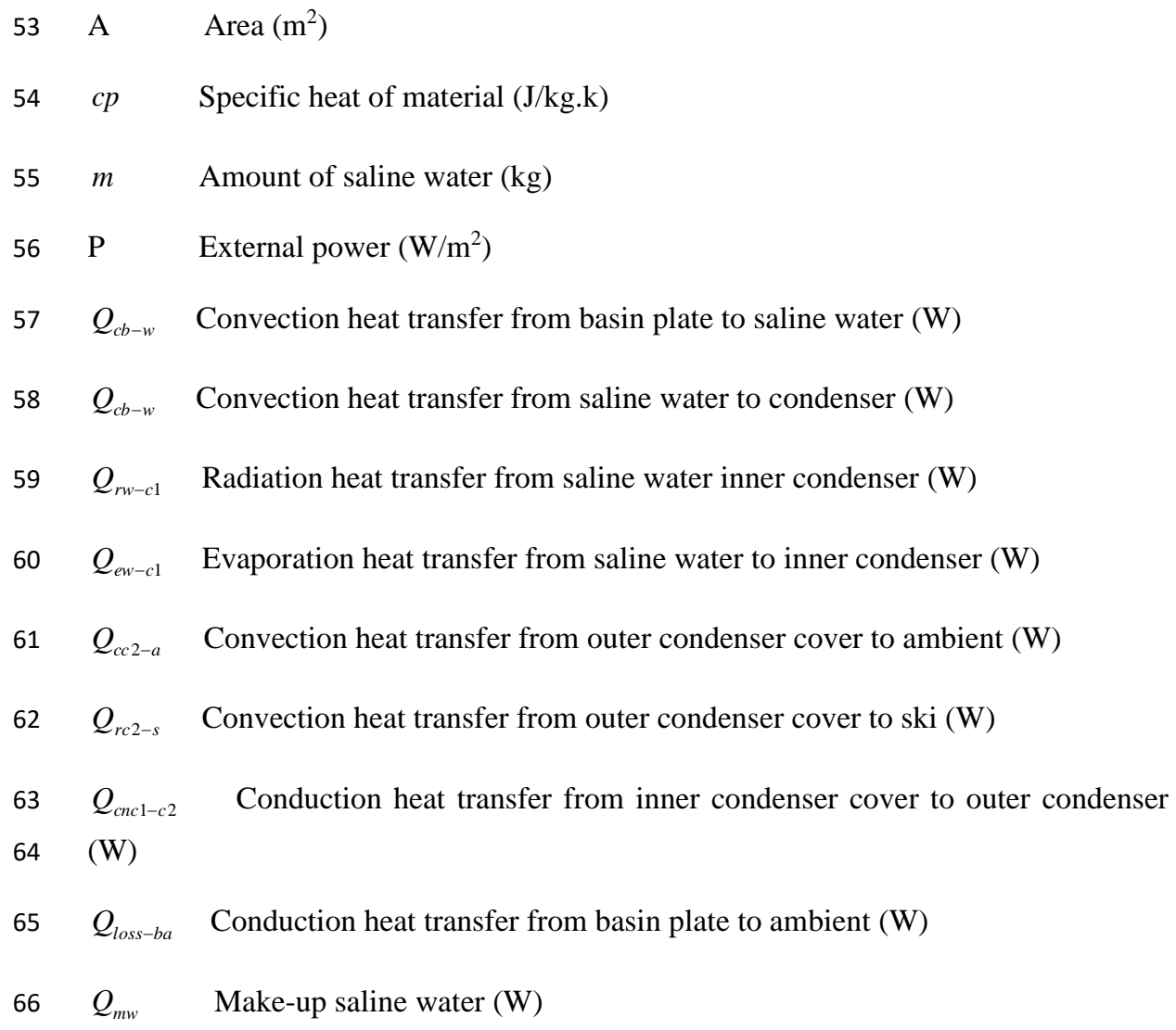




\section{Introduction:}

Water is an essential component of human health. Nearly $60 \%$ of the human body is composed of water. It is important to note that the individual's need for water varies from person another depending on the nature of the individual's daily physical activities and the drought proportion in the place where they live. Therefore, the individuals tend to drink sufficient amounts of water to prevent them from the drought. Consequently, it leads to drain the body's energy, and cause tired. The National Academy of Sciences has determined the amount of water that is recommended daily, namely 3.7 liters of water for males and 2.7 liters of water for females. In fact, these amounts include water obtained from drinking water, and eating other foods and beverages. Although three-quarters of earth is covered with water but, the clean water does not exceed $2.75 \%$, which is a low proportion comparing with saltwater.

Improving the performance of solar still depends mainly on decreasing condenser cover temperature and increasing saline water temperature. Enhancing the productivity of solar still has received significant attention from many researchers. The daily production of solar still depends on several factors such as climatic conditions (solar radiation intensity, ambient temperature, and wind speed), condensation surface inclination, insulation type and thickness, solar still geometry, the orientation of still and depth of salty water.

Bataineh and Abu Abbas (2020). studied numerically the effect of solar still productivity by adding vertical fins, external reflectors and both of them together at different seasons. The theoretical results show that the productivity has not been affected significantly by adding fins and the efficiency of still increase by $13 \%, 20 \%$, $28 \%, 33 \%, 37 \%$ and $46 \%$ in June, April, September, October, January, and December respectively when adding external reflectors. Bataineh and Abu Abbas (2020). investigated theoretically and experimentally, the effect of single sloped solar still performance when adding $\mathrm{Al}_{2} \mathrm{O}_{3}$ and $\mathrm{SiO}_{2}$ nanoparticles. The results show that the productivity of still boosted by $10 \%$ and $8.5 \%$, respectively, at $0.005 \mathrm{~m}$ saline water depth and $0.2 \%$ concentration of nanoparticles. Manokar et al (2020). Analyzed the performance of pyramid solar still at different saline water thickness, solar still with insulation material and solar still without insulation material. The experimental results inferred that the performance of still increase as saline water depth decrease and the productivity of still is improved 113 by integrate insulation material in the still. Khalifa et al (2009). Verified the effect of insulation thickness $(3,6$ and $10 \mathrm{~cm})$ on the efficiency of solar still. The experimental results described that the productivity of still increase as insulation thickness increase up to specific value $(6 \mathrm{~cm})$ beyond which the effect of increasing thickness become insignificant. Abu Abbas and Al-Abed Allah (2020) examined numerically the impact of condenser materials type and condenser incline on the performance of the solar still. The results reveal that the daily 
solar still productivity increases as transmissivity value of condenser material increase. In addition, it was noted that the maximum productivity in summer (May) was at the lowest condenser slope angle $\left(5^{\circ}\right)$ and it was decreased as the condenser slope angle increased. On the other hand, the maximum productivity of solar still in the winter season (January) was at $\left(20^{\circ}\right)$ and then decreased as the condenser slope angle increased. Dubey and Mishra (2019) examined the influence of three glass cover angles $\left(15^{\circ}, 30^{\circ}\right.$, and $\left.45^{\circ}\right)$ on solar still productivity. They found that the maximum productivity was obtained at $15^{\circ}$ tilt angle which was nearer to the latitude of Raghogarh, Guna. Kumar et al. (2008) examined the V-type solar still with floating charcoal absorber over the saline water in M.S.basin and with and without the boosting mirror. The yield increases with boosting the mirror, but overall efficiency reduces due to an increase in loss and condensate could be easily collected because of the collection at the center. Madhlopa et al. (2009) found out that utilizing multi evaporators and multi condensers have improved the solar still performance by $62 \%$. Hansen et al. (2017) enhanced solar still productivity by using fin shaped absorber configuration. Their results showed that the solar still efficiency increased by $25.75 \%$. E. Kabeel et al. (2018) investigated the effect of utilizing a different type of phase change materials (PCM) to enhance solar still performance. The theoretical results showed that the A48 type of PCM has the highest increase in efficiency reach up to 92\%. Al-harahsheh et al. (2018) conducted an experimental study on single slope solar still integrated with phase change material (PCM) and connected with a solar water collector to enhance basin water temperature of solar still. Zurigat et al. (2004) studied the effect of a regenerative concept on solar still performance. Their results illustrated that the performance of regenerative still concept is higher by $20 \%$ compared with conventional solar still. Nisrin Abdelal et al. (2018) conducted an experiment to study the effect of using absorber plates made of carbon fiber/nanomaterials-modified epoxy composites at different concentrations. Their results show that the productivity of still increase by $109 \%$ and $65 \%$ when adding $5 \%$ and 2.5\% Nano weight concentrations respectively. Agrawal et al. (2017) conducted experimental and theoretical study to investigate the effect of saline water depth (2 $\mathrm{cm}, 4 \mathrm{~cm}, 6 \mathrm{~cm}, 8 \mathrm{~cm}$ and $10 \mathrm{~cm}$ ) on solar distillation system productivity. Their results illustrated that the distilled water of solar distillation system increases as decreasing water depth. Hitesh et al. (2012) examined the effect of floating plates (such as galvanized iron and aluminum) on solar still productivity. It was observed that the aluminum plate enhanced the productivity of still more than galvanized iron plate.

Design of Experiment is an efficient tool for increasing the quantity of data gained from a study in addition to reducing the amount of data to be obtained, which, in this case is decreasing the number of trial runs. It should be remarked that all of the researches have studied the influence of utilizing one parameter at a time while keeping the other parameters fixed will not occur to understand the interaction. Here 
in this research, we collected all the parameters that could affect the active solar still system to show which parameters have the most significant effect and which of them does not has any influence when they are being together at the same time. Moreover, to explain the interaction between the most significant factors and their regression equations. In addition to highlight on the most important factors that create the optimal design for active solar still system.

\section{Methodology:}

\subsection{Description:}

The main components of active solar distillation system are shown in Fig. 1. The water tank is used as a make-up water system to compensate purified water. An external power device is used to heat the basin plate. Large proportion of heat will transfer by convection to the saline water while the rest of it will be lost outside by conduction through the bottom and the sides of still. The heat will be conveyed from the high saline water temperature to the internal surface of cooled condensation cover by evaporation, convection and radiation. The heated saline water will convey heat to the inner cooled condensation cover by evaporation, convection and radiation. Then part of heat will be transferred by conduction between two sides (from the inner to the outer surface) of the condenser, and by radiation and convection from the upper surface of the condenser to the surrounding air. Inclined condensation cover is used to move evaporated water to the water collector. Bottom and all sides of solar distillation system have a specific insulation material with a proper thickness to eliminate heat losses from heated saline water to the surrounding. Moreover, Fig. 2a and Fig. 2b show solar still with increasing condensation cover area and adding fan respectively to enhance convection heat transfer from upper surface of inclined surface to the ambient air. as a result, increasing condensation rate. Fig. 3 shows distilled water cycle for solar distillation system. . (1) .

.

2

3




\subsection{Mathematical model:}

A complete non liner differential equations model that shows the heat transfer and energy processes in the main components of the active solar distillation system has been written. These equations helped to calculate the quantity of the distilled water temperature and the condenser cover temperature at any time and at different system configurations. The theoretical results were founded by solving the main energy balance equations for the basin plate, saline water, the inner and the outer condenser covers of the active solar distillation system. The saline water, the basin plate, the inner and the outer condenser cover temperatures were evaluated every 5 hours to show the effect of changing different parameters on the solar distillation system productivity. The numerical model was solved by Matlab software. Energy balance equations for main solar still components are presented as follow:

As shown in Eq. (1), fraction of the external power connected with the solar distillation system is transmitted to the basin plate as heat and then it is transferred to saline water by convection. Other amount of energy is lost to the ambient through bottom insulation material by conduction.

$\mathrm{P}_{\mathrm{t}} \mathrm{A}_{\mathrm{b}}=m_{b} c p_{b} \frac{d T_{b}}{d t}+Q_{c b-w}+Q_{2 \mathbb{2} \leqslant 4 b a}^{213}$

The transient energy balance equation for the saline water is given as Eq. (2), fraction of heat is transmitted to saline water by convection. All heat gained is lost in two approaches; specific quantity of energy is stored in saline water due to its specific heat property. The rest of energy is released to the inner condenser cover by evaporation, convection and radiation.

$Q_{c b-w}=m_{w} c p_{w} \frac{d T_{w}}{d t}+Q_{c w-c 1}+Q_{e w-c 1}+Q_{r w-c 1}+222$

Energy balance equation for the inner condenser cover is presented as Eq. (3). The heat energy arrived from saline water surface is absorbed by the inner condenser cover and then released by conduction through thickness of the cover.

$Q_{c w-c 1}+Q_{e w-c 1}+Q_{r w-c 1}=m_{c} c p_{c} \frac{d T_{c 1}}{d t}+Q_{c 228 c 2}^{227}$

Energy balance equation for the outer condenser cover is shown as Eq. (4). The heat lost by conduction to the outer condenser cover is transferred by convection to the air and by radiation to the sky.

$Q_{c n c 1-c 2}=m_{c} c p_{c} \frac{d T_{c 2}}{d t}+Q_{r c 2-s k}+Q_{235-a}^{234}$ 


\subsection{Design of Experimental:}

Design of Experimental is a valuable tool for researchers and designers which used to develop any system design. This tool can reduce designing time and cost with high reliability than other designing approaches. As it is known, the main purpose of conducting an experiment is to be found which system parameters have most significant on the specific response (output of the system). Using this tool, it will be known the effected factors that improve the system and neglect the most fewer effected factors.

In this study, factorial design has been used to determine the most influence and not influence of 11 factors, interaction between them and regression equations for designing solar distillation system. Three responses have been evaluated which are distilled water, saline water temperature and inner condenser temperature.

\subsubsection{Factorial Design:}

A factorial design is an important type of design of experiments approaches. It is used to determine the most effected parameters to find the optimal design for the system of interest. Therefore, a huge time and tremendous effort could be saved instead of applying a full-scale simulation. Furthermore, the most valuable advantage of the factorial design is to find the regression equations and interactions between the factors that would be impossible to calculate in the other analysis approach. In order to achieve all the previous advantages, the factorial design method could set two values for each factor (levels), these levels and their values is determined by experience, then the researcher has to create configuration runs table using Minitab software according to probability counting rule $\left(2^{\wedge k}\right)$ where $\mathrm{k}$ is the number of factors each one has two levels (+1 value for a high level and -1 value for a low level.). Table. 1 below displays the main factors of interest

\subsubsection{Reduced Factorial $2^{\wedge(11-4)}$}

The main purpose of reduced factorial design that the system is performed with much less trials by sacrificing interactions for more than three factors. The reduced factorial which has been selected is $2^{\wedge}(\mathrm{k}-\mathrm{r})$ where $\mathrm{r}$ refers to number of reduced factors. Moreover, reduced factors have been chosen very carefully by checking the alias structure, resolution, balancing and orthogonally. In this study a $2^{\wedge}(11-4)$ reduced factorial has been used with $\mathrm{V}$ resolution, which means that the main effects and two-way interactions not confounded except with higher order interactions. Matlab has been used to simulate the suitable and necessary simulations and Minitab to investigate the main influence factors and interactions between them with high accuracy. 


\section{Numerical simulation assessment}

Fig. 4 shows the flowchart used to evaluate the most significant factors that have impacts on solar distillation system. The simulation starts with Minitab program to find the number of the solar still configurations using 11 factors. Determine type of analysis (reduced or full factorial), factors number and nature of runs (randomize or non-randomize runs) are the important steps in this software. Furthermore, a numerical model was written using Matlap program to analyze the effect of the solar still configurations calculated using Minitab program. Minitab is computer software which was developed to solve a mathematical model of the still components (condensation surface, saline water and basin plate) for different solar still configurations. The Temperature of the condensation cover, saline water and the basin plate were founded by solving the numerical model using Runge-Kutta method. All still components' temperatures and purified water were founded every 5 hours. Initial temperature values of different components of the solar still were equaled the ambient temperature value. Using these initial temperatures, the condensation cover, saline water and the quantity of distilled water were calculated. The procedures were repeated for every solar still configuration (run) which was taken from Minitab program. Finally, all solar still configurations results that calculated from MATLAP were analyzed using Minitab program to show their effects.

\section{Results:}

The results of mathematical and designing calculations could discover effect of different factors on active solar still responses. Three responses have been studied: amount of distilled water (mass output), water temperature, and condenser cover temperature. External power, basin area, water depth, insulation material, insulation thickness, condenser material, condenser area, thickness of condenser, air blowing system, Make-up water system, and ambient temperature are considered as variables to understand their influences on the mentioned responses. To be more effective, the simulation results were gained based on the design of experiment approach (DOE). The (DOE) was conducted using a reduced factorial method to show their direct effects, their interactions, and the optimization design for the system.

\subsection{Main effect plots on the responses:}

Fig. 5a, Fig. 5b and Fig. 5c showed the main factors influenced on the responses of active solar still system. The $\mathrm{x}$ axis shows responses values while the $\mathrm{y}$ axis shows 
the high and the low levels of the factors. It was clearly noted that, as inclination of the lines increase, the effect of the factors on the responses will be significant. The results found that the most important factors that enhance mass output are amount of external power, water depth, and basin area respectively. Where the mean mass output recorded at the high and low levels were $3.02 \mathrm{~L}$ and $1.24 \mathrm{~L}$ respectively for external power factor and $1.3 \mathrm{~L}$ and $2.8 \mathrm{~L}$ respectively for water depth factor. While, it is reached to about $2.8 \mathrm{~L}$ and $1.4 \mathrm{~L}$ at high and low levels of the basin area respectively. Moreover, other factors have a little effect on the system. Furthermore, the simulation results indicated that the water depth, the amount of external power, the air blowing system, and the condenser material respectively are the main factors that have the most influence on the water temperature and condenser cover temperature of the system while rest factors have a little effect on it as shown in Fig. 5b. and Fig. 5c.

\subsection{Interaction effect plots:}

The independent variables (factors) might interact with each other. It happens when the influence of one factor depends on the value of another factor. Moreover, the Interaction effects show that a third variable affects the relationship between an independent and dependent factor (responses). This kind of scheme represents the fit values of the dependent factor on the $y$-axis while the $\mathrm{x}$-axis displays the values of the first independent factor while the different lines describe the values of the second independent factor. About the interaction schemes, parallel lines show that there is no interaction between the two factors while the crossed lines and the lines that will be crossed infer that there is an interaction effect between the factors. Here are the figures for the factors that produced an interaction between each other for various responses. Fig. 6a showed that the interaction effect on mass output. It was clearly noted that (basin area*external power), (basin area*depth of water), (depth of water*external power), (depth of water * air blowing system) and (condenser material *depth of water) respectively have the greatest interaction effect between each other. For example, the scheme for (basin area*external power) explains that mass output level was higher when the external power and the basin area values were high. Conversely, the maximum mass output have been achieved when the external power and the basin area values were low. Fig. $6 \mathrm{~b}$ showed effect of the interaction on water temperature of the active solar still .it was shown that the highest interaction to produce maximum water temperature were between (depth of water $*$ air blowing system), (condenser material *depth of water), (depth of water*condenser area), (external power * air blowing system) and (depth of water*external power) respectively. While the interaction plot affected on condenser temperature was described in Fig. 6c. Whereas the important interaction effect were (depth of water * air blowing system), (condenser material *depth of water), (power * air blowing 
system), (depth of water*condenser area) and (depth of water*external power) respectively.

\subsection{Pareto charts of the standardized effects:}

Fig. 7 display the Pareto charts of the standardized effects for various responses. These charts determine the order of the most significant factors including main and interaction factors that effect on the response's values. It is clearly observed that the most influential factors on mass output are external power, depth of water, and basin area respectively. While in the water temperature and condenser cover temperature, the factors that have most significant effect are depth of water, external power, and air blowing system respectively.

\subsection{Regression equations:}

Regression has been conducted on the results of factorial to show the effects of these factors on the responses values. Eq. (5), Eq. (6), and Eq. (7) are the regression functions predicted from the reduced factorial study which find that the highest and lowest factors affected on three responses: distilled water, saline water temperature and condenser cover temperature respectively. The constant numbers refer to the factors affected ratio while the signals + , - refer to the high or low levels of the factors.

$$
\begin{aligned}
\text { Mass }= & -1.026-0.0349 \mathrm{~A}-8.1 \mathrm{~B}+0.480 \mathrm{C}+17.52 \mathrm{D}+0.0809 \mathrm{E}+4.67 \mathrm{~F} \\
& -0.0715 \mathrm{G}+0.000990 \mathrm{H}-0.1068 \mathrm{~J}+0.00196 \mathrm{~K}-0.1711 \mathrm{~L} \\
& +2.406 \mathrm{~A}^{*} \mathrm{D}-23.92 \mathrm{C}^{*} \mathrm{D}+0.005022 \mathrm{C}^{*} \mathrm{H}-0.02169 \mathrm{D}^{*} \mathrm{H} \\
& +3.194 \mathrm{D}^{*} \mathrm{~J}+1.554 \mathrm{D}^{*} \mathrm{~L}
\end{aligned}
$$

$$
\begin{aligned}
\mathrm{Tw}= & 16.72+4.36 \mathrm{~A}+3386 \mathrm{~B}+17.19 \mathrm{C}-10.7 \mathrm{D}-3.52 \mathrm{E}+41.5 \mathrm{~F} \\
& -0.627 \mathrm{G}+0.04329 \mathrm{H}-4.11 \mathrm{~J}+0.0179 \mathrm{~K}-0.761 \mathrm{~L} \\
& -759 \mathrm{~A}^{*} \mathrm{~B}+1.166 \mathrm{~A}^{*} \mathrm{E}-0.00571 \mathrm{~A}^{*} \mathrm{H}-2617 \mathrm{~B}^{*} \mathrm{C}-13448 \mathrm{~B}^{*} \mathrm{D} \\
& +58.2 \mathrm{D}^{*} \mathrm{E}-0.1492 \mathrm{D}^{*} \mathrm{H}+80.9 \mathrm{D}^{*} \mathrm{~J}-0.00433 \mathrm{E}^{*} \mathrm{H}+1.545 \mathrm{E}^{*} \mathrm{~J}- \\
& 0.00675 \mathrm{H}^{*} \mathrm{~J}
\end{aligned}
$$

$$
\begin{aligned}
\mathrm{Tc}= & 10.21+3.61 \mathrm{~A}+2095 \mathrm{~B}+0.70 \mathrm{C}+97.3 \mathrm{D}-3.20 \mathrm{E}+50.4 \mathrm{~F} \\
& -0.397 \mathrm{G}+0.04501 \mathrm{H}-3.61 \mathrm{~J}+0.0436 \mathrm{~K}-1.013 \mathrm{~L}-1203 \mathrm{~A}^{*} \mathrm{~B} \\
& +77.4 \mathrm{~A}^{*} \mathrm{D}-0.01053 \mathrm{~A}^{*} \mathrm{H}-1.815 \mathrm{~A}^{*}-18424 \mathrm{~B}^{*} \mathrm{D}+60.7 \mathrm{D}^{*} \mathrm{E}- \\
& 0.2414 \mathrm{D}^{*} \mathrm{H}+92.2 \mathrm{D}^{* \mathrm{~J}}-0.00717 \mathrm{E}^{*} \mathrm{H}+1.633 \mathrm{E}^{*} \mathrm{~J}-0.01207 \mathrm{H}^{*} \mathrm{~J}
\end{aligned}
$$




\subsection{Optimization Design:}

The designers should create the system by selecting the value of the optimal factors that could enhance mass output. As mentioned above, the maximum water output produced from the solar still could be achieved through increasing the saline water temperature and decreasing the condenser cover temperature. Table. 2 and 3 list the fit values and optimal design selected respectively, to achieve the optimal value for the mass output, saline water temperature and condenser cover temperature.

\section{Conclusion:}

The results of theoretical and statistical analyses of 11 factors on the active solar still system could be summarized as follows:

- The most important factors that can cause increasing in the mass output are the amount of external power, water depth, and the basin area respectively.

- The thickness of the condenser and the ambient air temperature do not affect the mean productivity

- Water depth, the amount of external power, the air blowing system, and the condenser material, respectively, are the main factors that have the most influence on the water temperature of the system.

- (Basin area*power), (basin area*depth of water), (depth of water*power), (depth of water * air blowing system) and (condenser material *depth of water), respectively, have the greatest interaction effect between each other that influence on mass output

- The significant interaction affected on saline water and the condenser temperatures are (depth of water * air blowing system), (condenser material *depth of water), (power * air blowing system), (depth of water*condenser area) and (depth of water*power) respectively.

- The optimal design for the system can be attained is by selecting:

- Higher external power, basin area, condenser thickness, ambient temperature and insulation thickness.

- Lower condenser area and depth of water.

- Using steel condenser material and fiberglass insulations rather than any other materials.

- Adding air blowing system and removing make-up system.

\section{Conflict of Interest}

The authors declare that they have no conflict of interest. 


\section{References:}

422 Abdelal, N., \& Taamneh, Y, Enhancement of pyramid solar still productivity using

423 absorber plates made of carbon fiber/CNT-modified epoxy composites,Desalination,

424 419(2017) 117-124.

425 Al-harahsheh, M.; Abu-Arabi, M.; Alzghoul, Z. Solar desalination using solar still

426 enhanced by external solar collector and PCM. Applied Thermal Engineering 2018,

427 128, 1030-1040. doi:10.1016/j.applthermaleng.2017.09.07.

428 Al-harahsheh Mohammad, Abu-Arabi, M., Mousa, H., \& Alzghoul, Z,Solar

429 desalination using solar still enhanced by external solar collector and PCM, Applied

430 Thermal Engineering, 128(2018) 1030-1040.

431 B.S. Kumar, S. Kumar, R. Jayaprakash, Performance analysis of a "V" type solar still

432 using a charcoal absorber and a boosting mirror, Desalination. 229 (2008) 217-

433 230.doi:10.1016/j.desal.2007.09.009.

434 Kabeel, A. E.; El-Samadony, Y. A. F., El-Maghlany, W. M. Comparative study on the 435 solar still performance utilizing different PCM. Desalination 2018, 432, 89-96.

436 doi:10.1016/j.desal.2018.01.01612.

437 Khaled M. Bataineh, Mohammad Abu Abbas, 2020. Improving the performance of

438 solar still by using nanofluids, vacuuming, and optimal basin water

439 thickness.Desalination and water treatment, 173, 105-116.

440 Khaled M. Bataineh, Mohammad Abu Abbas. Performance analysis of solar still

441 integrated with internal reflectors and fins. Solar energy. 2020. 205,22-36.

442 Khalifa, A. J. N., \& Hamood, A. M. (2009). Effect of insulation thickness on the 443 productivity of basin type solar stills: An experimental verification under local

444 climate. Energy Conversion and Management, 50(9), 2457

445 2461. doi:10.1016/j.enconman. 2009.06.007.

446 Madhlopa, A.; Johnstone, C. Numerical study of a passive solar still with separate

447 condenser. Renewable Energy 2009, 34(7), 1668-1677.

448 doi:10.1016/j.renene.2008.12.032.

449 M. Dubey, D.R. Mishra, Experimental and Theoretical evaluation of double slope 450 single basin solar stills: A study of heat and mass transfer, FME Trans. 47 (2019)

451 101-110. doi:10.5937/fmet1901101D. 
454 Mohammad Omar Abu Abbas, Malik Yousef Al-Abed Allah "Effect of Condenser 455 Materials Type and Condenser Slope on the Performance of Solar Still" Published in 456 International Journal of Trend in Research and Development (IJTRD), ISSN: 2394-

457 9333, Volume-7 | Issue-2 , April 2020,

458 URL: http://www.ijtrd.com/papers/IJTRD22078.pdf

459 Muthu Manokar, A., Taamneh, Y., Kabeel, A.E., Prince Winston, D., Vijayabalan, P., 460 Balaji, D., Sathyamurthy, R., Padmanaba Sundar, S., Mageshbabu, D., Effect of water

461 depth and insulation on the productivity of an acrylic pyramid solar still - An

462 experimental study, Groundwater for Sustainable Development), doi:

463 https://doi.org/10.1016/j.gsd.2019.100319, (2020).

464 Panchal, Hitesh, and Pravin K. Shah, Investigation on solar stills having floating 465 plates, International Journal of Energy and Environmental Engineering, 3.1 (2012): 8.

466 Samuel Hansen, R.; Murugavel, K. Enhancement of integrated solar still using 467 different new absorber configurations: An experimental approach. Desalination 2017, 468 422, 59-67. doi:10.1016/j.desal.2017.08.015.

469 Zurigat, Y. H., \& Abu-Arabi, M. K, Modelling and performance analysis of a 470 regenerative solar desalination unit, Applied Thermal Engineering, 24(2004) 10614711072. 
https://doi.org/10.5194/dwes-2020-22

Preprint. Discussion started: 27 July 2020

(c) Author(s) 2020. CC BY 4.0 License.

\section{$486 \quad$ List of figures}

487 Figure 1. Solar distillation system.

488 Figure 2. (a) increasing condensation cover area and (b) adding fan to solar still.

489 Figure 3. Distilled water cycle system.

490 Figure 4. System flow chart

491 Figure 5. main effect factors on (a) mass output, (b) water temperature and (c)

492 condenser cover temperature.

493 Figure 6. Interaction effect plot on (a) mass output, (b) water temperature and (c)

494 condenser cover temperature.

$495 \quad$ Figure 7. Pareto charts of the standardized effects for (a) mass output, (b) water

496 temperature and (c) condenser cover temperature.

497

498

List of Tables

499

Table 1: Description of factor levels.

500

Table 2. Responses fit values

502 Table 3. Values for optimal solar still design

503

504

505

506

507

508

509

510

511

512

513

514 


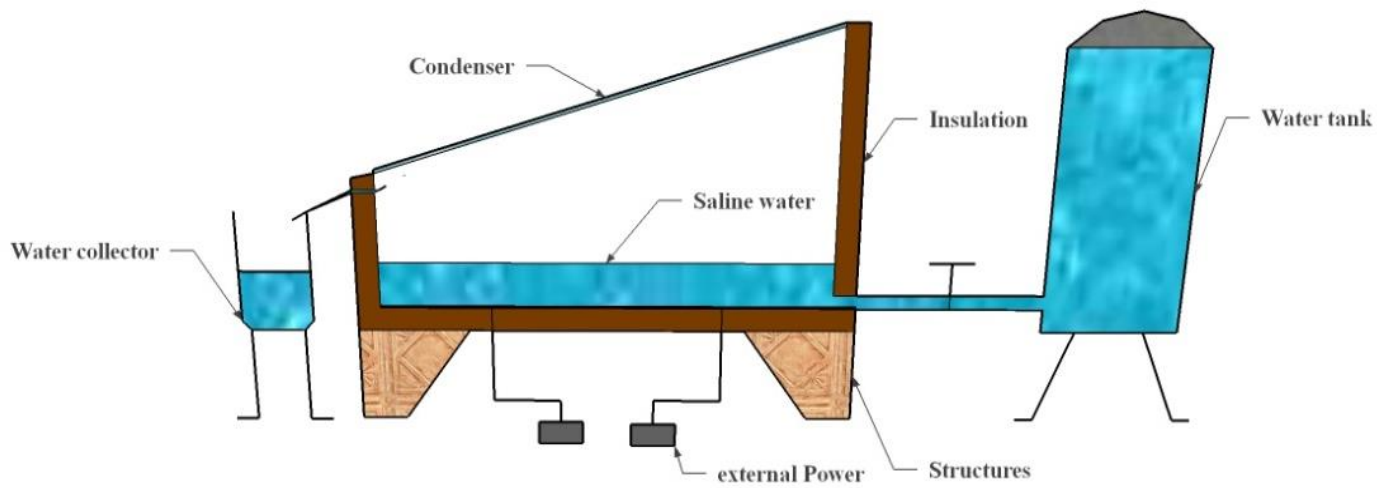

Figure 1. Solar distillation system.

516

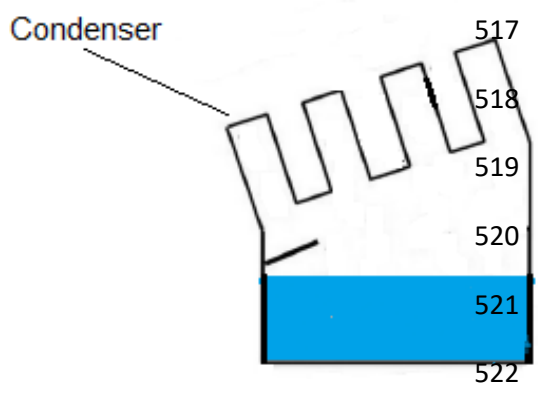

523

524
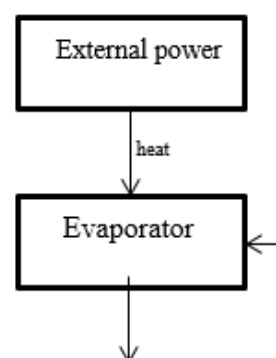

Saline water

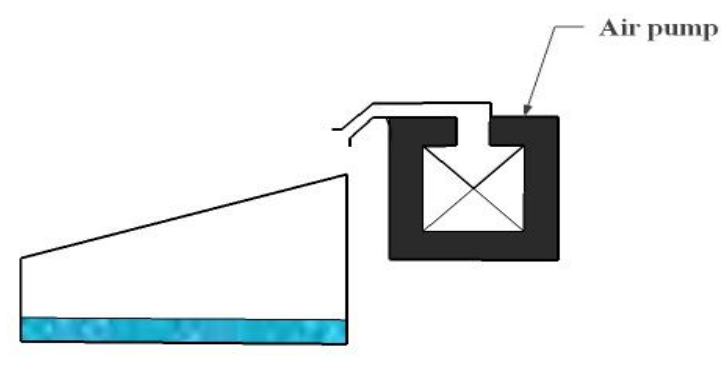

(b)

Figure 2. (a) increasing condensation cover area and (b) adding fan to solar still
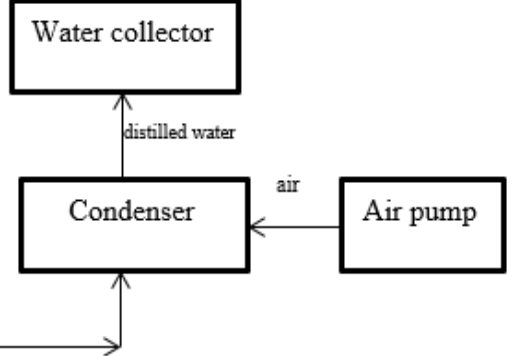

Figure 3. Distilled water cycle system. 
https://doi.org/10.5194/dwes-2020-22

Preprint. Discussion started: 27 July 2020

(c) Author(s) 2020. CC BY 4.0 License.

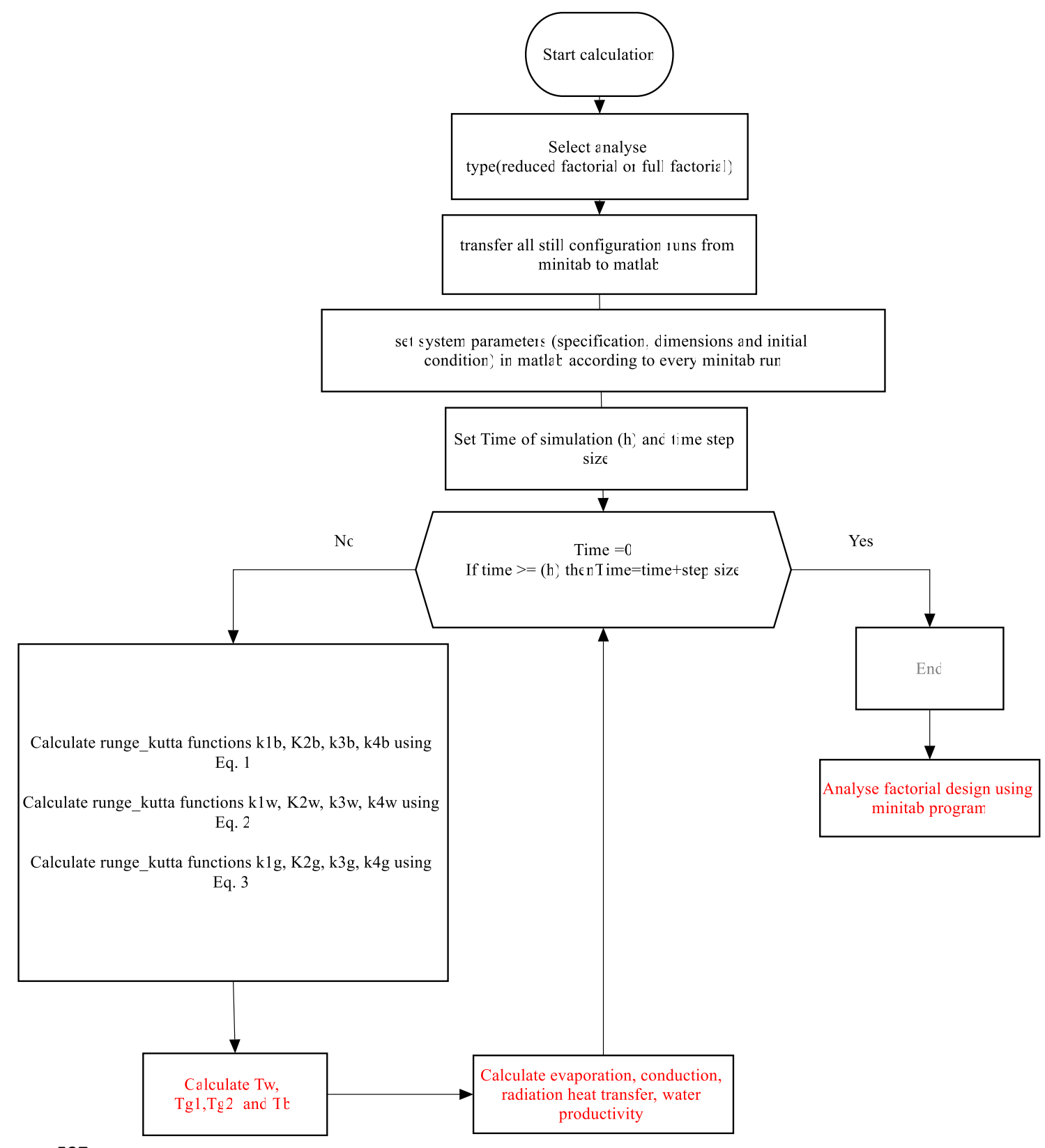

527

Figure 4. System flow chart 
https://doi.org/10.5194/dwes-2020-22

Preprint. Discussion started: 27 July 2020

(c) Author(s) 2020. CC BY 4.0 License.
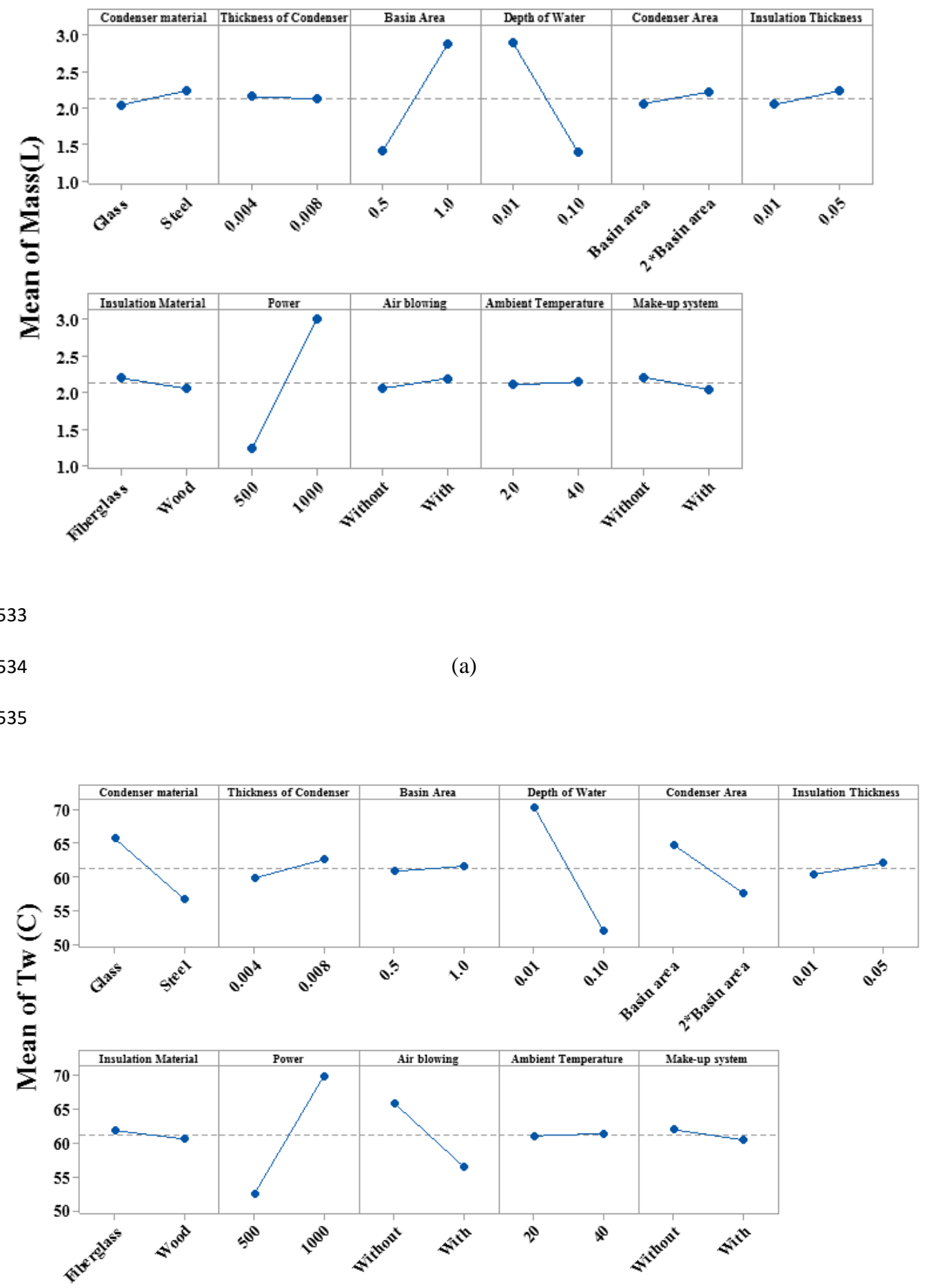
https://doi.org/10.5194/dwes-2020-22

Preprint. Discussion started: 27 July 2020

(c) Author(s) 2020. CC BY 4.0 License.

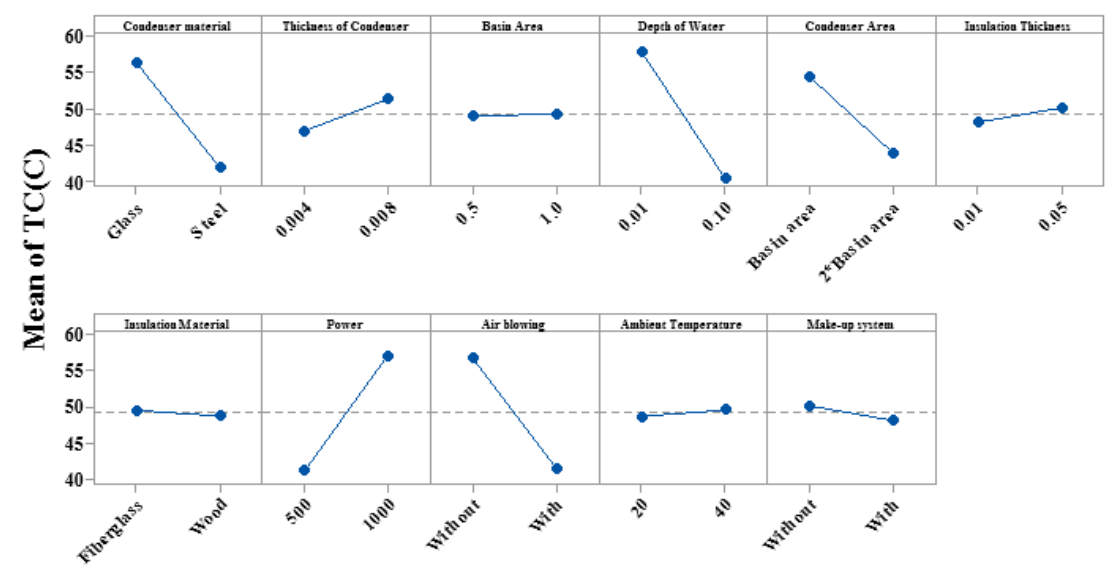

538

539

540

541
(C)

Figure 5. main effect factors on (a) mass output, (b) water temperature and (c) condenser cover temperature. 
https://doi.org/10.5194/dwes-2020-22

Preprint. Discussion started: 27 July 2020

(c) Author(s) 2020. CC BY 4.0 License.
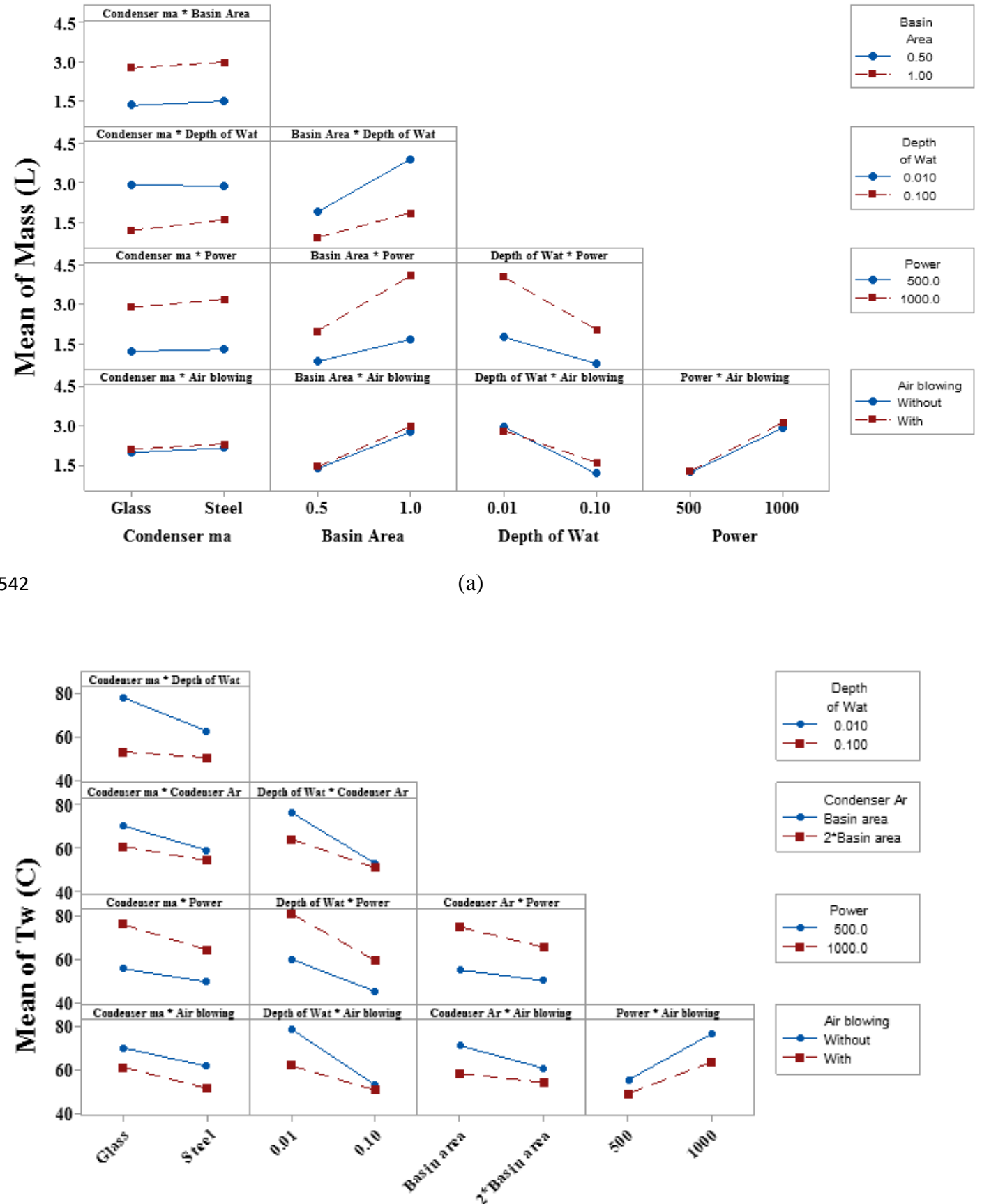

Condenser ma

Depth of Wat

Condenser Ar

Power

(b) 
https://doi.org/10.5194/dwes-2020-22

Preprint. Discussion started: 27 July 2020

(c) Author(s) 2020. CC BY 4.0 License.

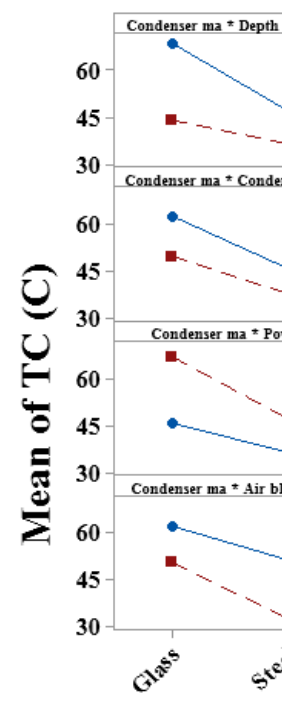

Condenser ma

Depth of Wat
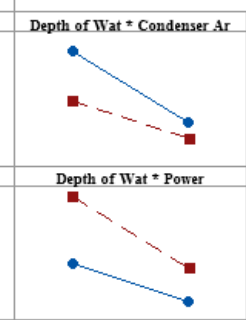

Condenser $\mathrm{Ar} *$ Power

-
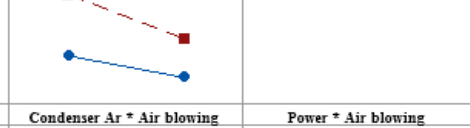

denser $\mathrm{Ar}$ * Air blowing
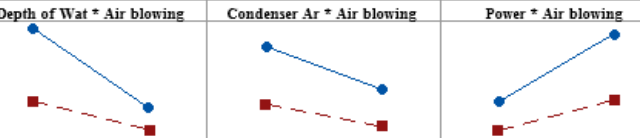

Without
548

549

550

551

552

553

554

555

556

557

558

559

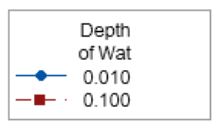

\section{Condenser Ar} - Basin area 2*Basin area
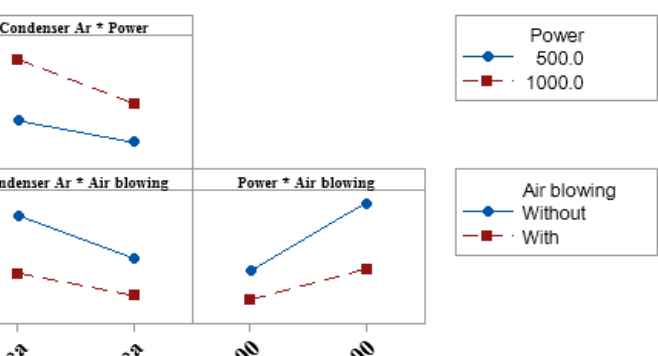

30

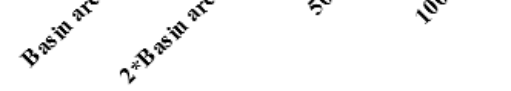

Power

Condenser Ar

(c)

Figure 6. Interaction effect plot on (a) mass output, (b) water temperature and (c) condenser cover temperature. 
https://doi.org/10.5194/dwes-2020-22

Preprint. Discussion started: 27 July 2020

(c) Author(s) 2020. CC BY 4.0 License.

Pareto Chart of the Standardized Effects

(response is Mass; $\alpha=0.05$; only 30 effects shown)
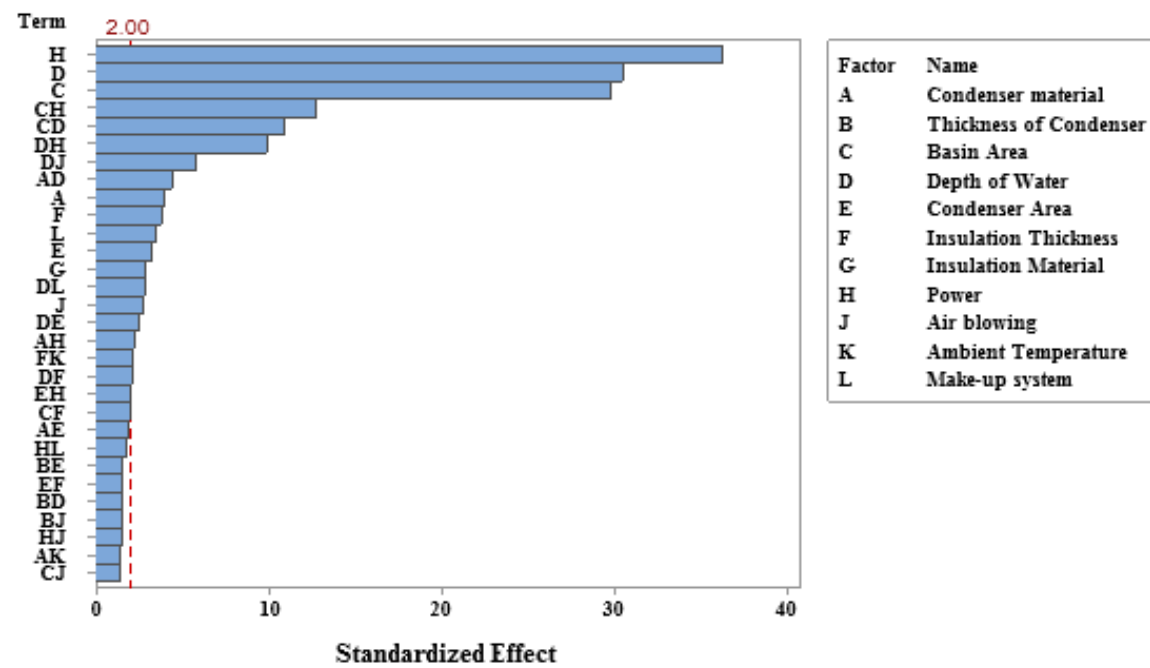

(a)

\section{Pareto Chart of the Standardized Effects} (response is $\mathrm{Tw} ; \alpha=0.05$; only 30 effects shown)

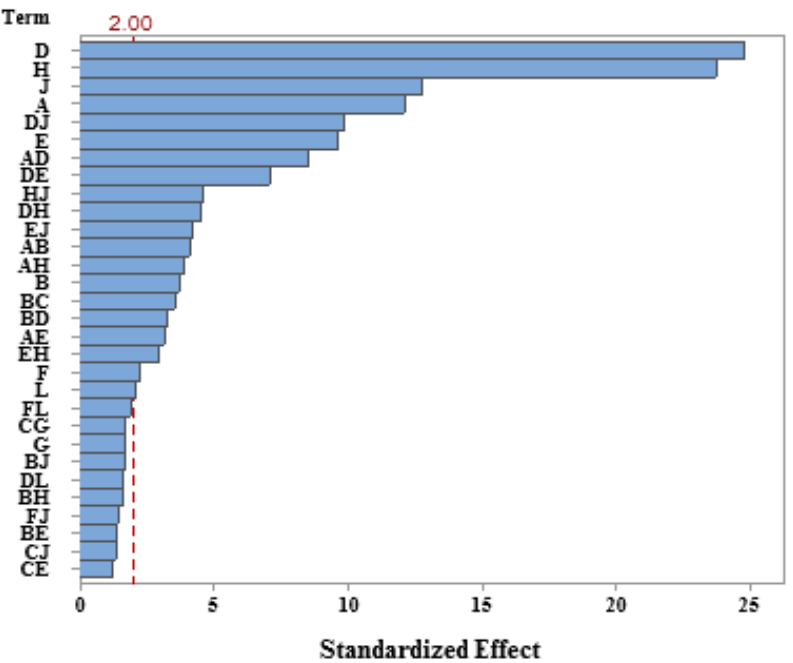

Name Condenser material Thickness of Condenser Basin Area Depth of Water Condenser Area Insulation Thickness Insulation Material Power Air blowing Ambient Temperature Make-up system 
https://doi.org/10.5194/dwes-2020-22

Preprint. Discussion started: 27 July 2020

(c) Author(s) 2020. CC BY 4.0 License.

Pareto Chart of the Standardized Effects

(response is Tc; $\alpha=0.05$; only 30 effects shown)
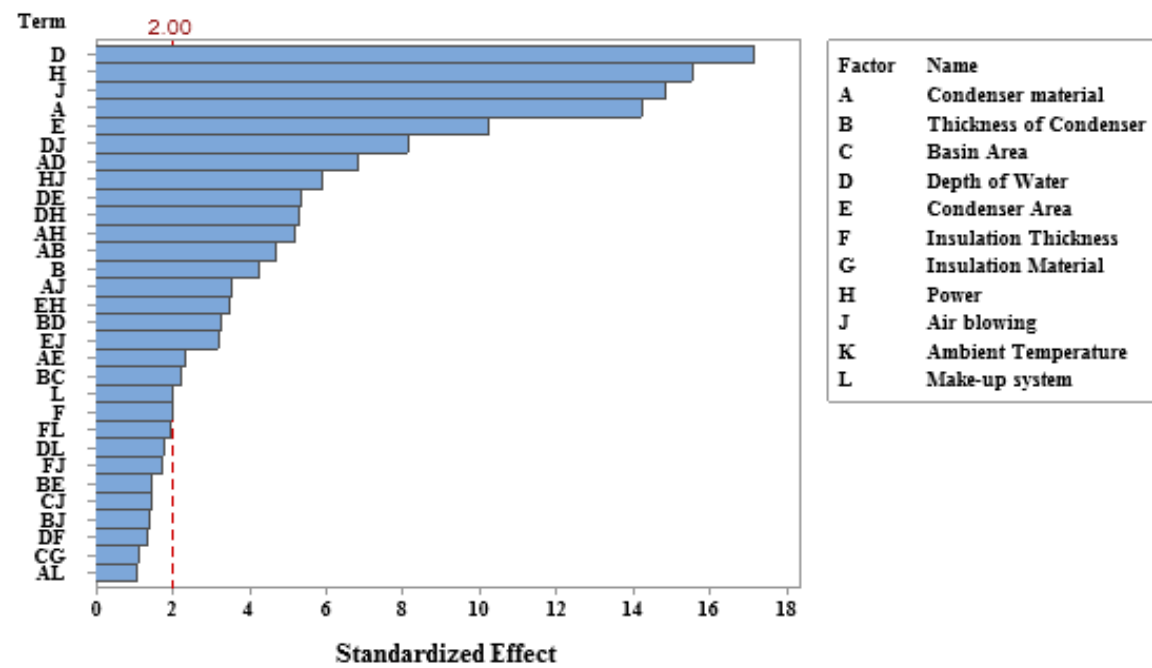

(c)

Figure 7. Pareto charts of the standardized effects for (a) mass output, (b) water temperature and (c) condenser cover temperature. 
https://doi.org/10.5194/dwes-2020-22

Preprint. Discussion started: 27 July 2020

(c) Author(s) 2020. CC BY 4.0 License.

583 Table 1: Description of factor levels.

\begin{tabular}{rcccc}
\hline Symbol & Factor Name & Low Level & High Level & Unit \\
\hline \hline A & Condenser Material & Glass & Steel & - \\
B & Thickness of Condenser & 4 & 8 & $\mathrm{~mm}$ \\
C & Basin Area & 0.5 & 1 & $\mathrm{~m}^{2}$ \\
D & Depth of Water & 1 & 10 & $\mathrm{~cm}$ \\
E & Condenser Area & Basin Area & $2 *$ Basin Area & $\mathrm{m}^{2}$ \\
F & Insulation Thickness & 1 & 5 & $\mathrm{~cm}^{2}$ \\
G & Insulation Material & Fiberglass & Wood & - \\
H & Power & 500 & 1000 & Watt \\
J & Air Blowing & Without & With & - \\
K & Ambient Temperature & 20 & 40 & $\mathrm{C}^{\circ}$ \\
L & Make-up Water System & Without & With & - \\
\hline
\end{tabular}

584

585 Table 2. Responses fit values

586

\begin{tabular}{cccccccc} 
Response & Goal & Lower & Target & Upper & Weight & Importanc 587 \\
\hline Tc & Minimum & & 29.238 & 121.323 & 1 & 1 & \\
Tw & Maximum & 43.080 & 122.702 & & 1 & 1 & 588 \\
Mass & Maximum & 0.306 & 6.474 & & 1 & 1 & 589
\end{tabular}

591

592

593

594

595

Table 3. Values for optimal solar still design

\begin{tabular}{cccccccc}
\multicolumn{9}{c}{ Thickness } & & & \\
Condenser & $\begin{array}{c}\text { of } \\
\text { Salutin }\end{array}$ & Depth of & Condenser & Insulation & Insulation \\
material & Condenser & Area & Water & Area & Thickness & Material \\
\hline 1 & Steel & 0.008 & 1 & 0.01 & Basin area & 0.05 & Fiberglass
\end{tabular}

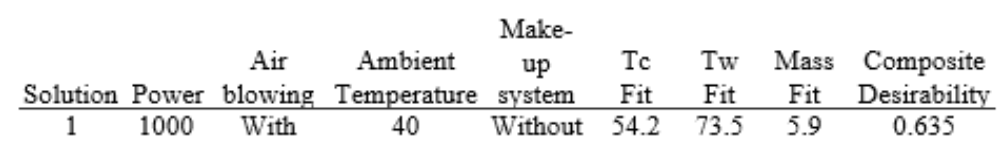

